\title{
KNOWLEDGE AND AWARENESS ABOUT DENTAL IMPLANTS FOR TREATMENT OF MISSING TEETH IN PATIENTS OF BAHADURGARH, HARYANA
}

\author{
Sakshi', Naresh Kumar2, Sibadatta Das ${ }^{3}$, Ashima Dahiya4, Kirti Sharma ${ }^{5}$
}

1MDS, Department of Prosthodontics, PDM Dental College and Research Centre, Bahadurgarh, Haryana.

${ }^{2}$ Associate Professor, Department of Physiology, SHKM Government Medical College, Nalhar, Nuh, Haryana.

${ }^{3}$ Associate Professor, Department of Physiology, SHKM Government Medical College, Nalhar, Nuh, Haryana.

${ }_{4}^{4}$ Assistant Professor, Department of Anatomy, SHKM Government Medical College, Nalhar, Nuh, Haryana.

${ }_{5}^{5}$ emonstrator, Department of Physiology, SHKM Government Medical College, Nalhar, Nuh, Haryana.

\section{ABSTRACT}

\section{BACKGROUND}

The goal of modern dentistry is to restore the patient to normal functions. In India, there is very limited use of Dental Implants by general population. The reason being lack of knowledge and awareness among the masses. Limited studies exist on assessing the knowledge and awareness regarding dental implant treatment options among patients who want replacement of missing teeth. Hence, the present study was carried out to assess the knowledge and awareness towards the use of dental implants as the option for replacement of missing tooth/ teeth.

\section{MATERIALS AND METHODS}

This is a cross-sectional study conducted among the patients visiting the OPD of Department of Prosthodontics and Crown and Bridge, PDM Dental College and Research Institute, Bahadurgarh, Haryana, between the period of March 2015 to February 2016. The survey was conducted through printed self-explanatory questionnaire, which included 9 questions in English as well as in Hindi with the intention to evaluate the knowledge and awareness of dental implants among the rural and suburban population of Bahadurgarh, Haryana.

\section{RESULTS}

The present study gives information about patient's knowledge and awareness about dental implants for the treatment of missing teeth in Prosthodontic Department of PDM Dental College, Bahadurgarh, Haryana. Study population of all the age groups were selected for ease of access and to increase the response rate being the prosthodontic patients.

\section{CONCLUSION}

There is a need for more knowledge and awareness among general patients about dental implant treatment for missing teeth. Thi s can be imparted by more dental education programme to enhance the level of understanding about merits of implant.

\section{KEYWORDS}

Dental Implants, Knowledge, Awareness, Prosthodontics.

HOW TO CITE THIS ARTICLE: Sakshi, Kumar N, Das S, et al. Knowledge and awareness about dental implants for treatment of missing teeth in patients of Bahadurgarh, Haryana. J. Evolution Med. Dent. Sci. 2018;7(03):294-297, DOI: $10.14260 /$ jemds $/ 2018 / 65$

\section{BACKGROUND}

The goal of modern dentistry is to restore the patient to normal functions, speech, health and aesthetics regardless of the atrophy, disease or injury of the stomatognathic system.(1) Responding to this ultimate goal, dental implants are the ideal option for people in good general oral health who have lost a tooth (or teeth) due to periodontal disease, an injury or some other reasons. Dental implants provide the patient with a fixed anchor for a tooth/ teeth that need not be removed at night or for cleaning as is there in removable prosthesis. Implants also do not require preparation of healthy asymptomatic teeth. In addition, the edentulous patient is provided a prosthesis that is both stable and in most cases

'Financial or Other Competing Interest': None.

Submission 27-12-2017, Peer Review 08-01-2018,

Acceptance 10-01-2018, Published 13-01-2018.

Corresponding Author:

Dr. Sibadatta Das,

H. No. 202, B2 Block,

SHKM Government Medical College,

Nalhar, Nuh, Haryana.

E-mail: sibashkmgmc@gmail.com

DOI: $10.14260 /$ jemds $/ 2018 / 65$

\section{(c) $($ ) $९$}

highly aesthetic. Dental implants were used originally for the treatment of edentulous patients and are associated with improved denture retention, stability, functional efficiency and quality of life.(2-4)

Although, implants have been a successful option for replacement of lost dentition for nearly five decades. Their use in dental treatment plan is still in its youth, because of limited awareness among patients. Patient awareness of dental implants must be provided in choice of the most appropriate option.(5) The problem is more magnified in the developing nations, where majority of population lacks education and awareness about dental implants as a treatment modality.(6) The level of awareness of dental implants varies among several studies in different countries and demographic areas.(7) According to a study by Zimmer et al(8) among 120 American subjects, public awareness and acceptance of dental implants were found to be high as well as to have a general positive attitude towards dental implants.

In India, there is very limited use of Dental Implants by general population. The reason being lack of knowledge and awareness among the masses. Limited studies exist on assessing the knowledge and awareness regarding dental 
implant treatment options among patients who want replacement of missing teeth. Hence, the present study was carried out in the Department of Prosthodontics, PDM Dental College, Bahadurgarh, Haryana to assess the knowledge and awareness towards the use of dental implants as the option for replacement of missing tooth/ teeth.

\section{MATERIALS AND METHODS}

This is a cross-sectional study among the patients visiting the OPD of Department of Prosthodontics and Crown and Bridge, PDM Dental College and Research Institute, Bahadurgarh, Haryana between the period of March 2015 to February 2016. All the respondents were informed about the aims and objectives of the study. The survey was conducted through printed self-explanatory questionnaire, which included 9 questions in English as well as in Hindi with the intention to evaluate the knowledge and awareness of dental implants among the rural and suburban population of Bahadurgarh, Haryana. Sample size was calculated with the formula-

$$
\mathrm{N}=\frac{\mathrm{Z}^{2} \mathrm{XPxA}}{\mathrm{E}^{2}}=\frac{4 \times 50 \times 50}{5 \times 5}=400
$$

Where $\mathrm{z}=$ population area constant $(1.96), \mathrm{P}=$ probability of success taken at $50 \%, \mathrm{~A}=$ probability of failure taken at $50 \%$ and $\mathrm{e}=$ standard error taken as $5 \%$. A total of 500 questionnaire forms were distributed among the subjects, out of which only 472 patients answered the questionnaire willingly. The demographic data of each patient including gender, age and education level were recorded before the survey. The surveyed population included males and females of all age groups ranging from 18 - 30 years, 31 - 45 years, 46 - 60 years and more than 60 years. The demographic data is shown in Table 1.

According to sample size calculation, we had to take more than 400 samples. We decided for 500 keeping in view that some patients will not reply, as we finally saw it was 28 no. of patients who did not reply. Sample size in anyways should not be below 400 . Anything more will give better results.

\section{RESULTS}

The present study gives information about patient's knowledge and awareness about dental implants for the treatment of missing teeth in Prosthodontic Department of PDM Dental College, Bahadurgarh, Haryana. Study population of all the age groups were selected for ease of access and to increase the response rate being the prosthodontic patients. In all 472 patients participated in the survey, $M=284$ (60.12\%); F= 188 (39.83\%). Table 1 summarises about the demographic data and Table 2 depicts the survey data of patients.

\begin{tabular}{|c|c|c|}
\hline Demographic Data & & No. and (\%) \\
\hline Gender & Male & $284(60.17)$ \\
\hline & Female & $188(39.83)$ \\
\hline Age (in years) & $18-30$ & $94(19.91)$ \\
\hline & $31-45$ & $127(26.90)$ \\
\hline & $46-60$ & $145(30.72)$ \\
\hline & $>60$ & $106(22.45)$ \\
\hline Education & Upto School & $345(73.09)$ \\
\hline & College & $115(24.36)$ \\
\hline & Postgraduates & $12(2.5)$ \\
\hline
\end{tabular}

\begin{tabular}{|c|c|c|}
\hline Monthly Income & Low & $306(64.83)$ \\
\hline & Medium & $55(11.65)$ \\
\hline & High & $63(13.34)$ \\
\hline \multicolumn{2}{|c|}{ Table 1. Demographic Data } \\
\hline
\end{tabular}

\begin{tabular}{|c|c|c|}
\hline Questionnaire & Categories & Response: n (\%) \\
\hline \multirow[t]{5}{*}{$\begin{array}{l}\text { Ways to replace } \\
\text { missing teeth }\end{array}$} & $\begin{array}{c}\text { Removable partial } \\
\text { denture (RPD) }\end{array}$ & $207(43.8)$ \\
\hline & $\begin{array}{l}\text { Fixed partial denture } \\
\text { (FPD) }\end{array}$ & 315 (66.73) \\
\hline & Complete denture (CD) & $205(43.43)$ \\
\hline & All & $195(41.31)$ \\
\hline & None of Above & $70(14.83)$ \\
\hline \multirow[t]{2}{*}{$\begin{array}{l}\text { Implant as a } \\
\text { substitute for } \\
\text { replacement of } \\
\text { missing teeth } \\
\end{array}$} & Yes & 295 (62.5) \\
\hline & No & $177(37.5)$ \\
\hline \multirow{4}{*}{\begin{tabular}{|c|} 
Source of \\
information about \\
implant
\end{tabular}} & Dentist & $120(40.67)$ \\
\hline & Friends and Family & $97(32.88)$ \\
\hline & $\begin{array}{l}\text { Newspaper, TV, } \\
\text { Advertisement }\end{array}$ & 65 (22.03) \\
\hline & Others & $13(4.4)$ \\
\hline \multirow[t]{4}{*}{$\begin{array}{l}\text { Effectiveness of } \\
\text { Implants over } \\
\text { other methods }\end{array}$} & More & $95(32.20)$ \\
\hline & Equal & $70(23.72)$ \\
\hline & Less & $15(5.08)$ \\
\hline & Do not Know & $115(38.98)$ \\
\hline \multirow[t]{4}{*}{$\begin{array}{c}\text { Advantages of } \\
\text { Implants }\end{array}$} & Fixed replacement & $180(61.01)$ \\
\hline & Looks better & $183(62.03)$ \\
\hline & Good in function & $249(84.40)$ \\
\hline & $\begin{array}{l}\text { Avoids grinding of } \\
\text { natural teeth }\end{array}$ & $178(60.33)$ \\
\hline \multirow[t]{3}{*}{$\begin{array}{c}\text { Disadvantages of } \\
\text { Implants } \\
\end{array}$} & High cost & 206 (69.83) \\
\hline & Need of surgery & $215(72.8)$ \\
\hline & Long treatment time & $198(67.11)$ \\
\hline \multirow[t]{4}{*}{$\begin{array}{l}\text { Lifespan of } \\
\text { Implants }\end{array}$} & Less than 5 years & $34(11.5)$ \\
\hline & $5-10$ years & $86(29.15)$ \\
\hline & $10-20$ years & 115 (38.98) \\
\hline & More than 20 years & $60(20.33)$ \\
\hline \multirow[t]{2}{*}{\begin{tabular}{|l|} 
Who should opt for \\
Implant treatment
\end{tabular}} & Everyone & 123 (41.69) \\
\hline & Only rich people & $172(58.31)$ \\
\hline \multirow[t]{2}{*}{\begin{tabular}{|c|} 
Would you like to \\
know more about \\
Implants \\
\end{tabular}} & Yes & $250(84.8)$ \\
\hline & No & $45(15.2)$ \\
\hline & \multicolumn{2}{|l|}{ Table 2. Survey Data } \\
\hline
\end{tabular}

\section{DISCUSSION}

Dental implant treatment has been at the forefront of clinical dental practice for over a decade and a half now.(9) With increasing rate of success of implant treatment, more patients are opting for dental implants as premier choice for replacement of missing teeth. However, a majority of Indian population is still unaware about the implants in dentistry. To assess the knowledge and awareness of implants among rural/ suburban population, this study was carried out among the patients visiting the OPD of Department of Prosthodontics and Crown and Bridge, PDM Dental College 
and Research Institute, Bahadurgarh, Haryana. A total of 500 questionnaire forms were distributed among the subjects, out of which only 472 patients answered the questionnaire willingly.

\section{Ways to Replace the Missing Teeth}

When asked about the different ways to replace the missing teeth, 207 (43.8\%) knew about Removable Partial Denture (RPD), which is in congruence with the study conducted by Satpathy et al(10) $(48.55 \%)$, while in studies conducted by Kohli et al,(11) Tomruck et al,(12) Kumar et al(13) and Narayanan et al(14) only $55 \%, 34.9 \%, 24.7 \%$ and $20.78 \%$ of the subjects respectively knew about RPD as treatment option for missing teeth. In the present study, 315 (66.73\%) patients knew about FPD as replacement of missing teeth which is in contrast to studies conducted by Kumar et al,(13) Narayanan et al(14) and Tomruck et al.(12) 205 (43.43\%) patients had a knowledge about complete denture, which is similar to studies conducted by Tomruck et al(12) and Satpathy et al.(10) 195 (41.31\%) knew about all options of replacing missing teeth in present study, while only $29.5 \%$ knew about same options in study conducted by Kumar et al.(13) 70 (14.83\%) of subjects did not know any option, which is similar to study by Kohli et al (11\%).(11)

Implant as a Substitute for Replacement of Missing Teeth About 295 (62.5\%) of surveyed population knew about implant as a substitute option for replacement of missing teeth, while 177 (37.5\%) did not know about implants. Studies conducted by Narayanan et al,(14) Kohli et al(11) and Santosh Kumar et al(15) had similar results in accordance with the present study about the knowledge of implant as a treatment option, while studies by Satpathy et al(10) and Kumar et al(13) show contrasting results about this question.

\section{Source of Information about Implants}

Out of 295 subjects who knew about implants, 120 (40.67\%) got to know about implants from dentist which is similar to studies conducted by Satpathy et al,(10) Kumar et al(13) and Tomruck et al.(12) 97 (32.88\%) told friends and family as a source of information conducted by Santosh et al(15) and Khosyal et al(16) showed influence of friends and family as $10 \%$ and $6.1 \%$ respectively. TV, Newspaper advertisement as a source of information about implants was answered by $65(22.03 \%)$ subjects, which is in contrast to studies by Santosh et al(15) (5\%) and Khosyal et al(16) $(8.8 \%)$, while study by Kumar et al(13) has similar result as in the present study.

\section{Effectiveness of Implants over other Methods}

95 (32.20\%) answered it is more which is similar to study by Suwal et al,(17) while $70(23.72 \%)$ said it is equal to other methods which is in contrast to study by Suwal et al. Only 15 (5.08\%) said implants are less effective than other methods, which is in congruence with the result of study conducted by Suwal et al. Majority 115 (38.98\%) answered that they do not know about the effectiveness of implants over other methods, which is quite lower than the same study.

\section{Main Advantage of Implants}

$180(61.01 \%)$ subjects answered that it is fixed replacement, while $183(62.03 \%)$ said implants look better. Majority of the surveyed population 249 (84.40\%) were good in function as the main advantage of implants, while 178 persons $(60.33 \%)$ had normal teeth.

Study by Kumar et al(13) showed almost similar results in case of opting looks better as the main advantage of dental implants, while study by Alqahtani et al(18) showed contrast in opting good in function as the main advantage of dental implants.

\section{Main Disadvantage of Dental Implants}

206 (69.83\%) persons said it is the high cost of implant treatment, which hinders them for treatment which is similar to the study by Kumar et al,(13) while 215 (72.8\%) said need of surgery was the main disadvantage of implant treatment. $198(67.11 \%)$ said it is the long treatment time which is the main disadvantage of treatment, which is in contrast to study conducted by Santosh Kumar et al.(15)

\section{Lifespan of Implant}

When asked about lifespan of dental implants 34 (11.5\%) said it is less than 5 years, while $86(26.15 \%)$ said it is $5-10$ years. $115(38.98 \%)$ said 10 - 20 years, while $60(20.33 \%)$ said it is more than 20 years. Study by Satpathy et al(10) and Alqahtani et al(18) show different results when asked about lifespan of implants except that similar percent of people stated lifespan of implant to be between 5 - 10 years.

\section{Who should opt for Implant Treatment}

123 (41.69\%) said everyone should go for implant treatment, while $172(58.30 \%)$ said only rich people should opt for implant treatment. This is almost similar to the study conducted by Narayana et al(14) in which $49.79 \%$ said everyone should opt for implant, while $56.45 \%$ said only rich should opt for implant treatment.

\section{Would you like to know more about Implants}

$250(84 \%)$ said they wanted to know more about implant treatment, while $45(15.2 \%)$ said that they did not want to know about implants. The results were in accordance to the study by Alqahtani(18) (82.6\%) and Satpathy (89.35\%).(10)

\section{CONCLUSION}

There is a need for more knowledge and awareness among general patients about dental implant treatment for missing teeth. This can be imparted by more dental education programme to enhance the level of understanding about merits of implant.

\section{REFERENCES}

[1] Miche CE. Rationale for dental implants. In: Contemporary implant dentistry. $3^{\text {rd }}$ edn. MosbyElsevier, 2014:3-25.

[2] Adell R, Eriksson B, Lekholm U, et al. Long term follow up study of osseointegrated implants in the treatment of edentulous jaws. Int J Oral Maxillofac Implants 1990;5(4):347-59.

[3] Albrektsson T, Zarb G, Worthington P, et al. The long term efficacy of currently used dental implants: a review and proposed criteria of success. Int J Oral Maxillofac Implants 1986;1(1):11-25. 
[4] Albrektsson T, Blomberg S, Branemark A, et al. Edentulousness-an oral handicap. Patient reactions-to treatment with jawbone anchored prosthesis. J Oral Rehabil 1987;14(6):503-11.

[5] Guyatt GH, Cook DJ. Health status, quality of life and the individual. JAMA 1994;272(8):630-1.

[6] Saha A, Dutta S, Vijaya V, et al. Awareness among patients regarding implants as a treatment option for replacement of missing teeth in Chattisgarh. J Int Oral Health 2013;5(5):48-52.

[7] Chowdhary R, Mankani N, Chandraker NK. Awareness of dental implants as a treatment choice in urban Indian populations. Int J Oral Maxillofac Implants 2010;25(2):305-8.

[8] Zimmer CM, Zimmer WM, Williams J, et al. Public awareness and acceptance of dental implants. Int J Oral Maxillofac Implants 1992;7(2):228-32.

[9] Pommer B, Zechner W, Watzak G, et al. Progress and trends in patients' mindset on dental implants. I: level of information, sources of information and need for patient information. Clin Oral Implants Res 2011;22(2):223-9.

[10] Satpathy A, Porwal A, Bhattacharya A, et al. Patient awareness, acceptance and perceived cost of dental implants as a treatment modality for replacement of missing teeth: a survey in Bhubaneswar and Cuttack. International Journal of Public Health Dentistry 2011;2(1):1-7.

[11] Kohli S, Bhatia S, Kaur A, et al. Public knowledge and acceptance of dental implant treatment in Malaysian population. Journal of Interdisciplinary Dentistry 2014;4(2):76-80.
[12] Tomruk OC, Özkurt-Kayahan Z, Şençift K. Patients' knowledge and awareness of dental implants in a Turkish subpopulation. J Adv Prosthodont 2014;6(2):133-7.

[13] Kumar S, Chauhan A. Knowledge and awareness of dental implants in India: an exploratory study. Int J Oral Health Med Res 2015;2(4):29-33.

[14] Narayanan V, Karuppiah P, Rajasekar A, et al. Awareness among patients regarding dental implants as a treatment option for replacing missing teeth in melmaruvathur population. Int J Prosthodont Restor Dent 2016;6(1):6-9.

[15] Santhosh KMP, Gayathri MM. Knowledge and awareness among patients about dental implants. J Pharm Sci \& Res 2016;8(5):351-4.

[16] Khosya B, Devaraj CG. Awareness of dental implants as a treatment modality among people visiting Mahatma Gandhi dental college \& hospital, Jaipur. NJMR 2015;5(1):61-3.

[17] Suwai P, Basnet BB, Shrestha B, et al. Knowledge, attitude, and awareness regarding dental implants among patients visiting a university hospital and its teaching districts. J Dent Implant 2016;6(2):57-61.

[18] Alqahtani F, Alqahtani H, Alshalwi A, et al. Patients' awareness of a dental implant as an option for tooth replacement: a survey in Alkharj Province, Saudi Arabia. Int J Dent Oral Health 1(3). Doi http://dx.doi.org/10.16966/2378-7090.113. 